Prepared in cooperation with Resource Ecology Laboratory, Colorado State University

\title{
Large Scale Wyoming Transportation Data: A Resource Planning Tool
}

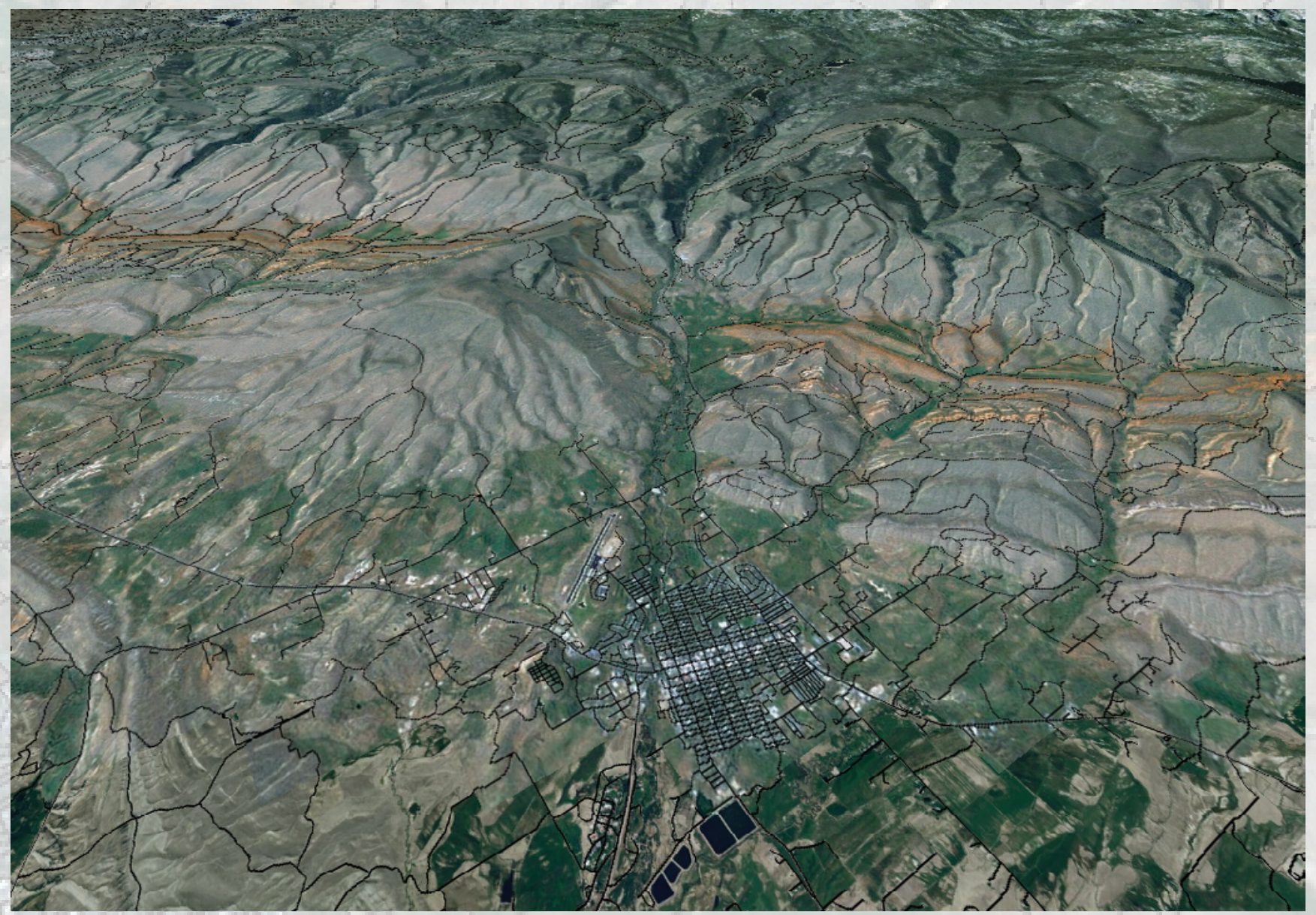

Data Series 821

U.S. Department of the Interior

U.S. Geological Survey 
COVER. A birds-eye view of Lander Wyoming transportation, looking toward the Wind River mountain range (generated with ESRI ArcGlobe®). 


\section{Large Scale Wyoming Transportation Data: A Resource Planning Tool}

By Michael S. O'Donnell, Tammy S. Fancher, Aaron T. Freeman, Abra E. Ziegler,

Zachary H. Bowen, and Cameron L. Aldridge

Prepared in cooperation with Resource Ecology Laboratory, Colorado State University

Data Series 821 


\section{U.S. Department of the Interior \\ SALLY JEWELL, Secretary}

\section{U.S. Geological Survey \\ Suzette M. Kimball, Acting Director}

U.S. Geological Survey, Reston, Virginia: 2014

For more information on the USGS - the Federal source for science about the Earth, its natural and living resources, natural hazards, and the environment, visit http://www.usgs.gov or call 1-888-ASK-USGS.

For an overview of USGS information products, including maps, imagery, and publications, visit http://www.usgs.gov/pubprod

To order this and other USGS information products, visit http://store.usgs.gov

Any use of trade, product, or firm names is for descriptive purposes only and does not imply endorsement by the U.S. Government.

Although this report is in the public domain, permission must be secured from the individual copyright owners to reproduce any copyrighted materials contained within this report.

Suggested citation:

O’Donnell, M.S., Fancher, T.S., Freeman, A.T., Ziegler, A.E., Bowen, Z.H., and Aldridge, C.L., 2014, Large scale Wyoming transportation data-A resource planning tool: U.S. Geological Survey Data Series 821, 21 p., http://dx.doi.org/10.3133/ds821.

ISSN 2327-638X (online) 


\section{Contents}

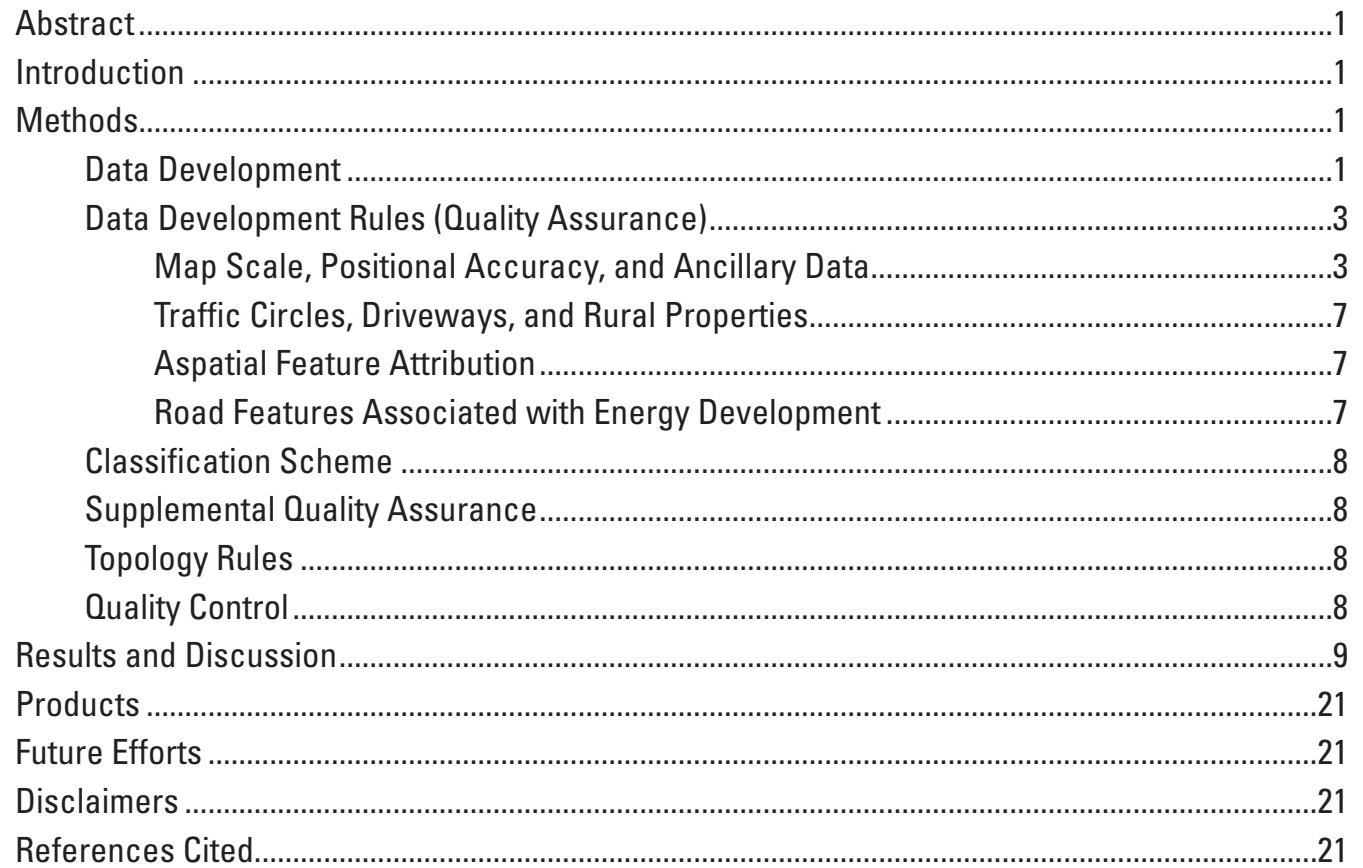

\section{Figures}

1. Wyoming road data set with symbolized road classes ...................................................

2. The location of counties, major cities, and major interstates within Wyoming .................6

3. Difficulties distinguishing between classes '1700210' and '1700209' .................................

4. Example where we did not use the 'absent on the 2009 NAIP imagery' rule because fixing these roads will require more time than if they were deleted and re-digitized from scratch

5. An outcome where we deleted pre-existing roads and re-digitized the roads versus attributing the pre-existing roads as 'absent on the 2009 NAIP imagery', and then fixing those roads to match the imagery

6. GIS data contains a portion of a road feature that is not visible in the imagery; therefore, GIS technicians interpolate where the road likely exists while digitizing......11

7. Distribution of five randomly selected 7.5-minute quadrangles within each 1:100,000-scale quadrangle used for evaluation and assessment of roads digitized within the state of Wyoming

8. Distribution and the number of omission errors by $1: 100,000$-scale quadrangle for roads digitized within the state of Wyoming

9. Distribution and the number of aspatial errors by 1:100,000-scale quadrangle for roads digitized within the state of Wyoming....

10. Distribution and the number of spatial errors by $1: 100,000$-scale quadrangle for roads digitized within the state of Wyoming....

11. Distribution of roads modified or added relative to original data set while assuming a fuzzy logic of 1 meter..... 
12. Distribution of roads modified or added relative to original data set while assuming a fuzzy logic of 5 meters .

13. Distribution of roads modified or added relative to original data set while assuming a fuzzy logic of 9 meters

\section{Tables}

1. Road classification scheme for 2009 National Agriculture Imagery Program (NAIP) roads within Wyoming ..............................................................................................

2. Detailed definitions of transportation scheme with pictorial examples ............................

3. List of Wyoming county codes used for assigning road class attributes ..........................7

4. Topology rules enforced on the updated 2009 National Agriculture Imagery Program roads data set. .......................................................................................12

5. Linear distances quantified for pre-existing and updated 2009 National Agriculture Imagery Program roads across Wyoming....................................................................14

6. Summary statistics quantified for original and updated road data across the state

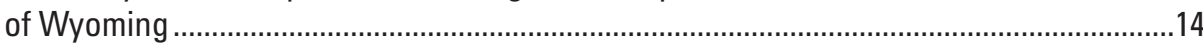




\section{Conversion Factors}

SI to Inch/Pound

\begin{tabular}{lll}
\hline Multiply & By & To obtain \\
\hline Length & & \\
\hline foot (ft) & 0.3048 & meter (m) \\
mile (mi) & 1.609 & kilometer $(\mathrm{km})$ \\
yard (yd) & 0.9144 & meter (m) \\
\hline & & \\
SI to Inch/Pound & By & To obtain \\
\hline Multiply & & \\
\hline Length & 3.281 & foot (ft) \\
\hline meter (m) & 0.6214 & mile (mi) \\
kilometer $(\mathrm{km})$ & 1.094 & yard (yd) \\
meter $(\mathrm{m})$ & &
\end{tabular}

Horizontal coordinate information is referenced to the insert datum name (and abbreviation) here, for instance, "North American Datum of 1983 (NAD 83)" 


\title{
Large Scale Wyoming Transportation Data: A Resource Planning Tool
}

\author{
By Michael S. O'Donnell', Tammy S. Fancher', Aaron T. Freeman², Abra E. Ziegler², Zachary H. Bowen', \\ and Cameron L. Aldridge ${ }^{3}$
}

\section{Abstract}

The U.S. Geological Survey Fort Collins Science Center created statewide roads data for the Bureau of Land Management Wyoming State Office using 2009 aerial photography from the National Agriculture Imagery Program. The updated roads data resolves known concerns of omission, commission, and inconsistent representation of map scale, attribution, and ground reference dates which were present in the original source data. To ensure a systematic and repeatable approach of capturing roads on the landscape using on-screen digitizing from true color National Agriculture Imagery Program imagery, we developed a photogrammetry key and quality assurance/quality control protocols. Therefore, the updated statewide roads data will support the Bureau of Land Management's resource management requirements with a standardized map product representing 2009 ground conditions. The updated Geographic Information System roads data set product, represented at 1:4,000 and $+/-10$ meters spatial accuracy, contains 425,275 kilometers within eight attribute classes. The quality control of these products indicated a 97.7 percent accuracy of aspatial information and 98.0 percent accuracy of spatial locations. Approximately 48 percent of the updated roads data was corrected for spatial errors of greater than 1 meter relative to the pre-existing road data. Twenty-six percent of the updated roads involved correcting spatial errors of greater than 5 meters and 17 percent of the updated roads involved correcting spatial errors of greater than 9 meters. The Bureau of Land Management, other land managers, and researchers can use these new statewide roads data set products to support important studies and management decisions regarding land use changes, transportation and planning needs, transportation safety, wildlife applications, and other studies.

\footnotetext{
${ }^{1}$ U.S. Geological Survey

${ }^{2}$ Cherokee Services Group, Contracted to U.S. Geological Survey

${ }^{3}$ Department of Ecosystem Science and Sustainability and Natural Resource Ecology Laboratory, Colorado State University, in cooperation with U.S. Geological Survey
}

\section{Introduction}

The Bureau of Land Management (BLM) Wyoming State Office maintains a statewide Geographic Information System (GIS) road database. The U.S. Geological Survey (USGS) Fort Collins Science Center assisted the BLM by updating the GIS roads data (while excluding other transportation types) using aerial photography from the 2009 National Agriculture Imagery Program (NAIP). Figure 1 illustrates the final road product and the affiliated road classes. This report is a summary of the final products and accuracy assessment.

The updated roads data resolves known concerns of omission, commission, and inconsistent representation of map scale, attribution, and ground reference dates within previous roads GIS products. The BLM requires accurate roads data for developing ecoregional assessments, environmental assessments, environmental impact statements, resource management plans, travel management plans, and records of decision, as well as using these to quantify disturbances associated with wind energy, oil and gas activities, and other anthropogenic land uses. These products will support the needs of BLM planning as well as provide a statewide, large-scale representation of roads data; this representation will support many planning and research endeavors within Wyoming.

\section{Methods}

\section{Data Development}

BLM provided the pre-existing roads database, which we used as a starting point for developing the products outlined in this report. We used ESRI ${ }^{\circledR}$ ArcGIS ${ }^{\circledR}$ (versions 9.3 and 10.0; Environmental Systems Research Institute, Redlands California, 2009-2010) for all data development and quality control assessments. We acquired all true color 2009 NAIP imagery from the U.S. Department of Agriculture as MrSID ${ }^{\circledR}$ compression files for each county in Wyoming. Although we did not investigate the spatial accuracies of the NAIP data, we used ancillary data that would identify errors in positional accuracy 


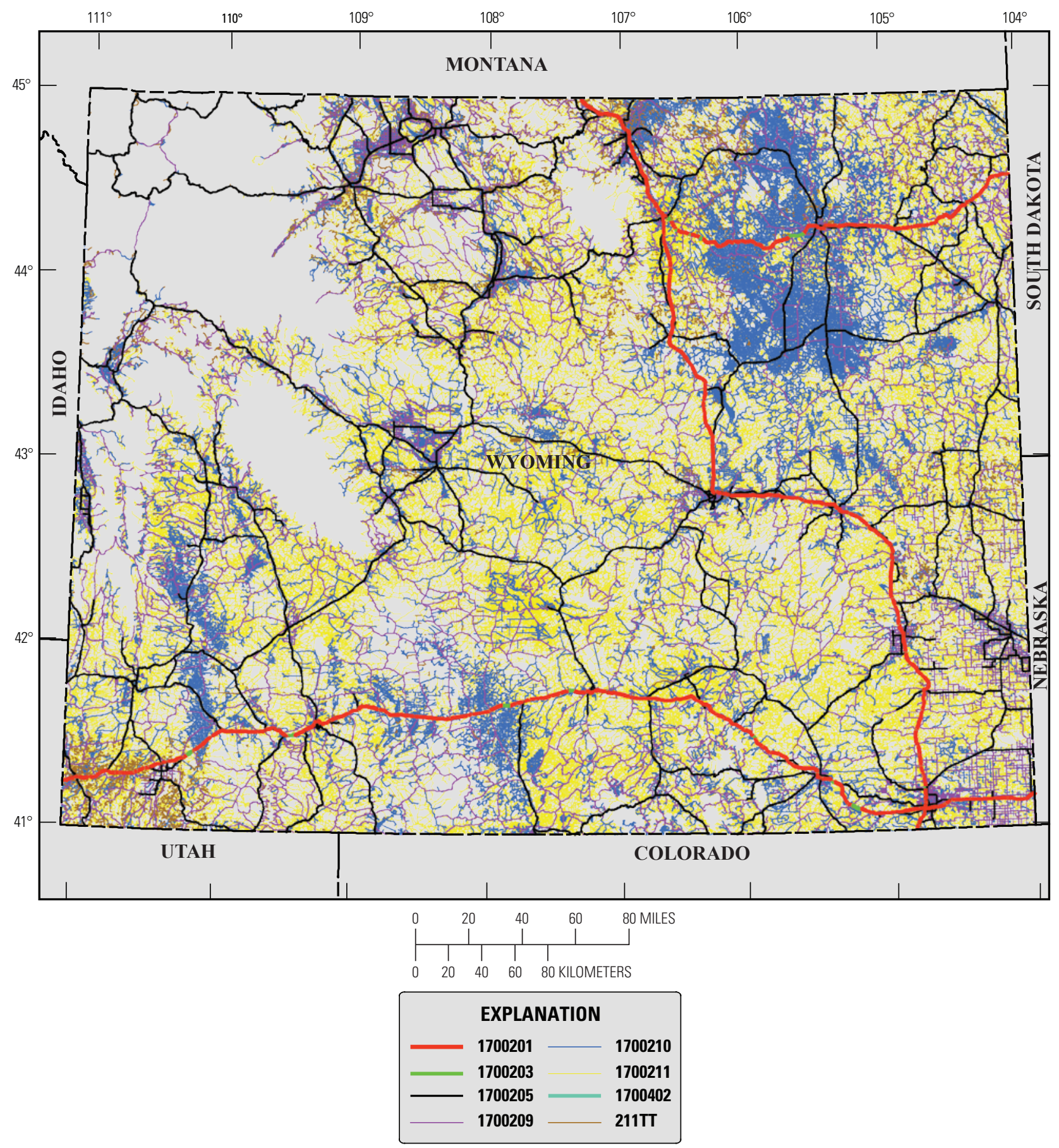

Figure 1. Wyoming road data set with symbolized road classes. 
during digitization (for example, Bing® Maps 2010-2012) and existing roads data to assist with attribution of road classes (for example, National Park Service and U.S. Forest Service). We found one substantial area with such errors, and we updated and attributed these roads using the 2006 NAIP imagery (documented at the feature level within the data set table) instead of the 2009 NAIP imagery used throughout the rest of the state.

We hand digitized new road features from the August 2009 NAIP imagery using decision rules and an ESRI file geodatabase ${ }^{\circledR}$ design that BLM and USGS developed jointly. We systematically updated the roads using a tracking grid comprised of 330,260 polygons (988 meters [m] $\times 780 \mathrm{~m}$ ), which facilitated systematic assessment and digitization at a visual scale of 1:4,000. During digitization efforts, each tracking polygon was examined for errors of omission and commission (except for commission of class 1700211, see tables 1-2), spatial inaccuracy of 10 meters or greater, and aspatial errors (for example, errors related to attribution of the features). We split the pre-existing Wyoming roads data set into blocks, for GIS technicians to digitize and correct topology errors. After digitization, we edge-matched and reconciled attribute differences between blocks and then combined these into a single data set. We then snapped the resulting data to the Wyoming state boundary and validated topology (correcting any errors) within the final data set.

Two stages of this project include quality assurance (QA) and quality control (QC). Quality assurance entails a standard operating procedure of data development rules minimizing variations of interpreting feature classification within the NAIP data. The second stage, quality control, is the process of identifying errors in the updated data products, which we then corrected for the final deliverables.

\section{Data Development Rules (Quality Assurance)}

The USGS and BLM collectively identified the following rules prior to digitizing efforts. We established these rules based on expert knowledge, investigation of the original data set, and BLM needs for spatial and aspatial accuracy. After digitization began, we identified additional rules, which we document below (see the "Supplemental Quality Assurance" section).

\section{Map Scale, Positional Accuracy, and Ancillary Data}

- Digitize data using a visual map scale of 1:4,000.

- Use a tracking grid while digitizing.

- Use centerlines to represent all road features.

- Retain existing digitized roads regardless of road width and digitize new roads if they were greater than 4 meters wide.

- Update positional accuracy of existing road data when roads deviated more than 10 meters at a visual scale of $1: 4,000$.

- Do not use multi-part features.

- Use ancillary data for updating road features if we consider the data reliable, consistent with the 2009 NAIP (for example, higher resolution aerial photography), and necessary.

Table 1. Road classification scheme for 2009 National Agriculture Imagery Program (NAIP) roads within Wyoming. (BLM, Bureau of Land Management; DLG, USGS Digital Line Graph)

\begin{tabular}{lll}
\hline ENTITY_LABEL & BLM Surface Management Map Symbol & DLG Description \\
\hline 1700201 & Primary highway, hard surface & Primary route, class 1, symbol undivided \\
1700203 & Primary highway, hard surface-lanes divided & Primary route, class 1, divided, lanes separated \\
1700205 & Secondary highway, hard surface & Secondary route, class 2, symbol undivided \\
1700209 & Light duty, hard, or aggregate surface & Road, class 3, symbol undivided (Road or street, class 3) \\
1700210 & Streets, roads graded, drained, natural surface & Road, class 4 (Road or street, class 4) \\
1700211 & Four wheel drive, rough bladed or two-tracked & $\begin{array}{c}\text { Trail (class 5, other than four-wheel drive vehicle), see } \\
\text { photogrammetric key for details about why these } \\
\text { surface }\end{array}$ \\
1700402 & Newly added (per 2009 NAIP) two-track features & Not applicable \\
\hline
\end{tabular}


Table 2. Detailed definitions of transportation scheme with pictorial examples (photogrammetric key).

[NAIP, National Agriculture Imagery Program; BLM, U.S. Bureau of Land Management; DLG, USGS Digital Line Graph; m, meters]

\begin{tabular}{ccc}
\hline ENTITY_LABEL & Description & Example \\
\hline $\begin{array}{c}\text { Primary highway, } \\
\text { hard surface }\end{array}$ & $\begin{array}{c}\text { Primary route, class 1, symbol undivided; includes Interstate and } \\
\text { U.S. numbered highways with interchanges. Vehicles access these } \\
\text { highways via ramps and these roads will have multiple lanes. The } \\
\text { opposing traffic lanes may be divided by a median strip. } \\
\text { These roads are classified as unseparated and they always require a } \\
\text { route number that is the same as the largest road at the intersection } \\
\text { (that is, interstate) }\end{array}$ & $\begin{array}{c}\text { Depicts opposing the center of the median strip: } \\
\text { down the }\end{array}$ \\
& &
\end{tabular}

1700203: $\quad$ Primary route, class 1, divided, lanes separated; Interstate and

Primary highway, hard surface-lanes

divided
U.S. numbered highways with interchanges. Vehicles access these highways via ramps and these roads will have multiple lanes. The opposing traffic lanes are divided by a wide median strip.

These roads are classified as divided/separated and they always require a route number.

1700205:

Secondary highway, hard surface

Secondary route, class 2, symbol undivided; includes state highways and county highways that do not have limited road access as required by class ' 1700201 ' and '1700203'. These roads are always hard surface (concrete or asphalt). They will have intersections with other roads, may be divided or undivided, and have multi-lane or singlelane characteristics.

Roads in this category always require a route number.

1700209:

Light duty, hard, or aggregate surface
Road, class 3, symbol undivided; improved roads for which there is no route descriptor to indicate administrative responsibility. These roads are generally narrower than roads in class ' 1700205 ', can include hard surface (concrete or asphalt) or aggregate surface and are usually undivided with single-lane characteristics.

These roads usually have a local name along and intersect with other roads and driveways. Roads in this category always require a route number.
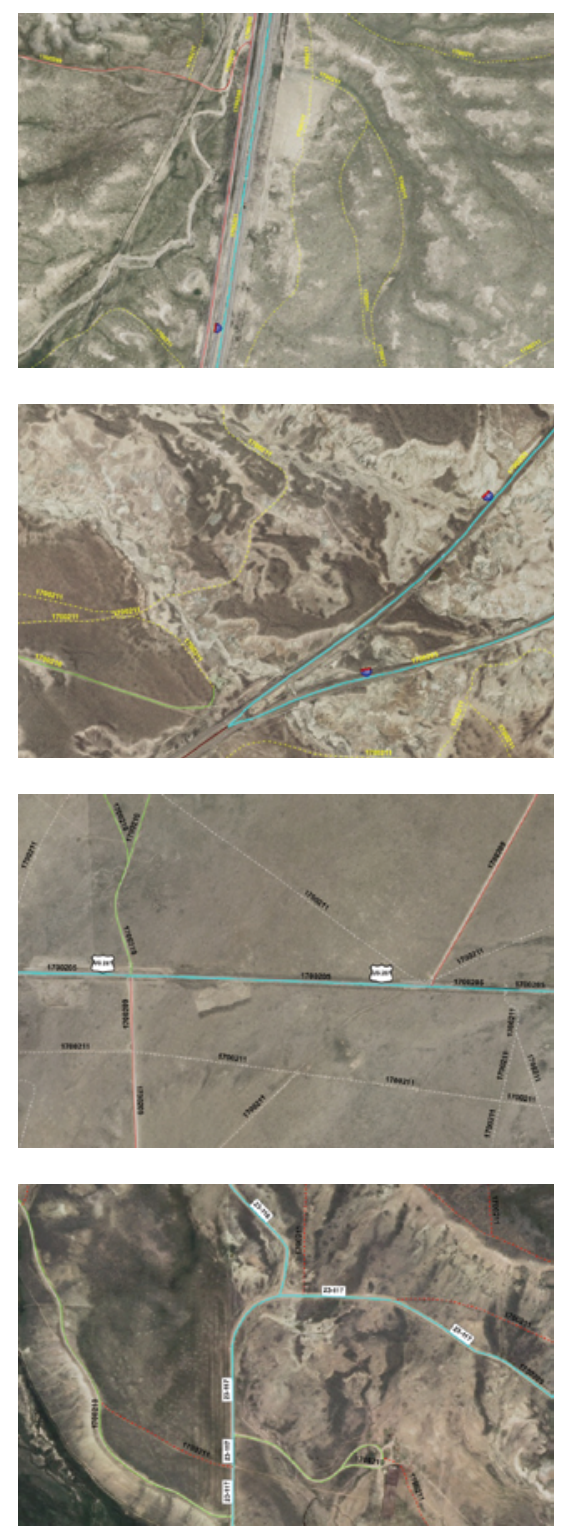
Table 2. Detailed definitions of transportation scheme with pictorial examples (photogrammetric key).-Continued

[NAIP, National Agriculture Imagery Program; BLM, U.S. Bureau of Land Management; DLG, USGS Digital Line Graph; m, meters]

\section{ENTITY_LABEL}

Description

1700210:

Streets, roads, graded, drained, natural surface

1700211

(does not represent DLG 1700211): four wheel drive, rough graded, drained, natural surface
Road or street (road's main function is transportation, while streets facilitate public interaction), class 4; used for local traffic and usually has a single lane of traffic in each direction. In urban areas, this is a street not belonging in categories ' 1700205 ' or ' 1700209 '. In rural areas, this is a short-distance road connecting the smallest towns. Scenic park roads, unimproved or unpaved roads, minor residential roads, and industrial roads are included in this category.

The road may or may not have a state or county route number.

These features usually represent a one-lane dirt trail and found almost exclusively in rural areas. Sometimes the road is called "fire" or "logging" and may include an abandoned railroad grade where the tracks have been removed. However, this feature class contains DLG '1700211' and DLG '1700212,' which are defined below.

DLG '1700211': These represent trails that are labeled in various ways such as "foot trail," "pack trail," or "bicycle trail" although the type of trail is not encoded. Trails that were once an old railroad grade are not included in this classification category.

DLG '1700212': Road, class 5, four-wheel-drive; Usually one-lane dirt trail and found almost exclusively in rural areas. Sometimes the road is called a fire road or logging road and may include an abandoned railroad grade where the tracks have been removed.

This attribute for the original BLM data and the delivered product are a combination of DLG codes '1700211' (Trail) and '1700212'

(Road, class 5, four-wheel drive). These previously assigned attributes were not changed, and any new two-track roads identified during digitization were added to $211 \mathrm{TT}$ instead of this class.

\section{Example}

County highway route numbers include a numeric county code followed by the route number (for example, 23-117 = Sublette County Rd 117; see table 3 and fig. 2).
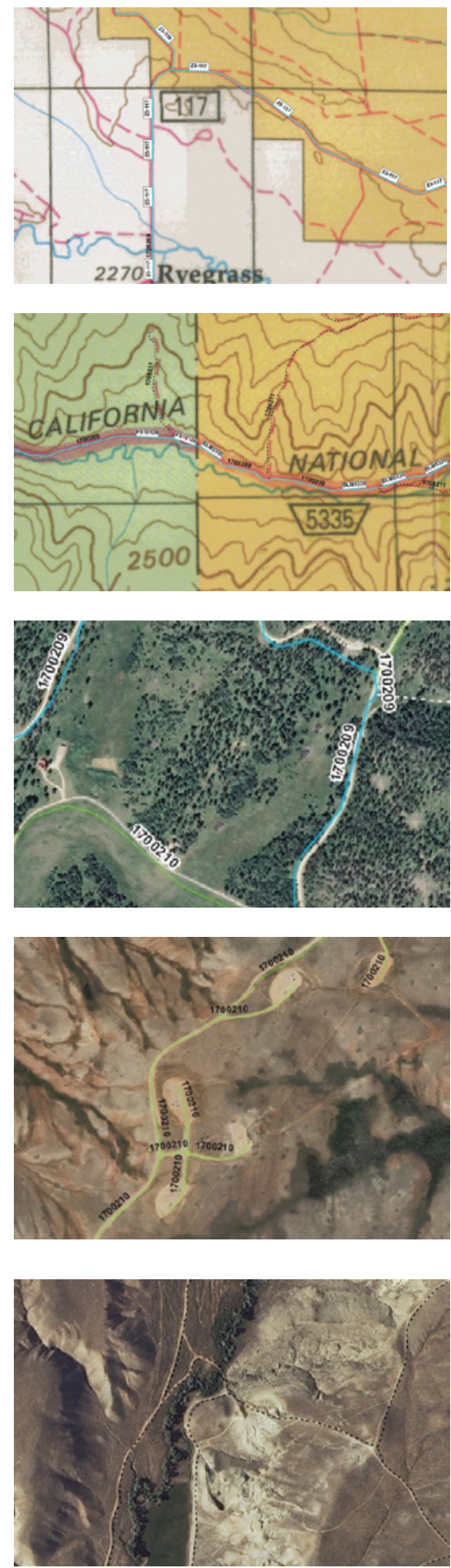


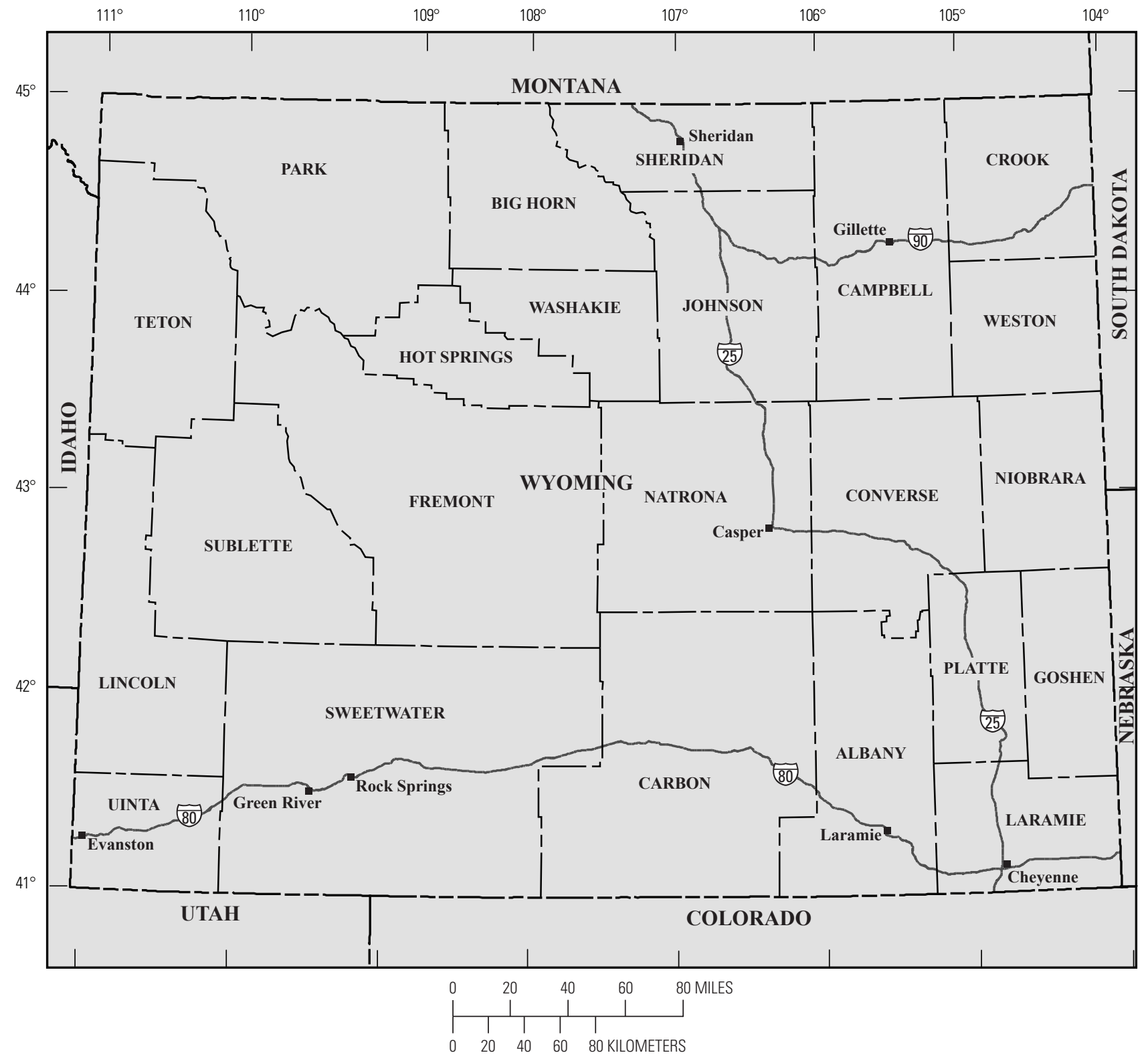

Figure 2. The location of counties, major cities, and major interstates within Wyoming. 
Table 3. List of Wyoming county codes used for assigning road class attributes (Source: http://www.epa.gov/enviro/ $\mathrm{html} / \mathrm{codes} / \mathrm{wy} . \mathrm{html}$ ). (FIPS, Federal Information Processing Standards)

\begin{tabular}{lclc}
\hline \multicolumn{1}{c}{ County Name } & FIPS Code & County Name & FIPS Code \\
\hline ALBANY & 1 & NATRONA & 25 \\
BIG HORN & 3 & NIOBRARA & 27 \\
CAMPBELL & 5 & PARK & 29 \\
CARBON & 7 & PLATTE & 31 \\
CONVERSE & 9 & SHERIDAN & 33 \\
CROOK & 11 & SUBLETTE & 35 \\
FREMONT & 13 & SWEETWATER & 37 \\
GOSHEN & 15 & TETON & 39 \\
HOT SPRINGS & 17 & UINTA & 41 \\
JOHNSON & 19 & WASHAKIE & 43 \\
LARAMIE & 21 & WESTON & 45 \\
LINCOLN & 23 & & \\
\hline
\end{tabular}

- Maintain the BLM map projection: Universal Transverse Mercator, North American Datum 1983, Zone 12 North (ESRI ${ }^{\circledR}$ projection file: NAD_1983 UTM_Zone_12N).

\section{Traffic Circles, Driveways, and Rural Properties}

- Classify traffic circles using the highest road class entering the traffic circle.

- Collect maintained access roads to rural residences if they are greater than 100 meters $(\mathrm{m})$ long and greater than $4 \mathrm{~m}$ wide (attribute as ' 1700210 ', streets, roads graded, drained, natural surface).

- Map driveways and cul-de-sacs to be consistent with the pre-existing data.

\section{Aspatial Feature Attribution}

- Attribute new data in accordance with the pre-existing road classification scheme (table 1).

- Correct omission and commission of features, per the 2009 NAIP imagery, for all attribute classes except for commission of '1700211' (4-wheel drive, rough bladed or two-tracked surface).

- Transfer features that represent commission errors into an independent data set and attribute the feature appropriately (Pres09NAIP = "N"; to indicate 'absence on the 2009 NAIP imagery').

- Do not attribute roads that underpass other features (that is, road segments were not divided at underpasses), including other roads, railroads, buildings, and runways.

- In the pre-existing data, class ' 1700211 ' also included trails that were only distinguishable at large scales (less than 1:1,000). The BLM and USGS agreed that it was not feasible to capture features with this detail given the timeframe and funding.

\section{Road Features Associated with Energy Development}

- Collect all roads to oil and gas well pads and facilities regardless of length.

- Terminate newly collected roads at the margins of oil and gas well pads and facility footprints. 
- Decision rules for distinguishing a two-track from a utility cable/pipeline scar:

- Any long and straight feature, without a bend in rough terrain, is likely a buried utility cable/pipeline and hence this feature was not mapped.

- Classify long, straight features with visible signs of a continuous or discontinuous vegetated center and a width greater than or equal to $4 \mathrm{~m}$ as a twotrack (211TT).

- Moderately long, straight features in flat terrain, with a width greater than or equal to $4 \mathrm{~m}$, that have an obvious to and from destination (for example, from a private residence to a water source) are classified as a two-track (211TT).

- We did not capture long, skinny, straight features that abruptly change directions at approximately $90^{\circ}$ in a rural area because these are likely a buried utility cable/pipeline.

\section{Classification Scheme}

Table 1 identifies the attributes assigned to each linear feature within the GIS data. This classification scheme parallels the BLM and the USGS Digital Line Graph (DLG) attribution standard (http://nationalmap.gov/standards/dlgstds. html) with the exception of newly added two-track roads. Table 2 provides a detailed definition and graphic representation of each road class, which we used as our photogrammetry key while developing the GIS data products. Due to problems with commission of ' 1700212 ' in class ' 1700211 ', this feature class contains two classifications of roads, which we explain in detail within table 2 .

\section{Supplemental Quality Assurance}

We identified several additional scenarios occasionally encountered while digitizing and attributing the road data. We describe these scenarios and identify how we addressed each one for additional quality assurance.

1. Attribution rules

2. Differentiating between classes was sometimes difficult or impossible; therefore, we required the use of ancillary data (higher resolution Bing Maps, National Park Service, and U.S. Forest Service data) to aid with attribution of features. For example, figure 3 demonstrates the difficulties in distinguishing between road classes ' 1700210 ' and '1700209.'

3. Correcting absence/presence of spatial features

- We did not use the 'absent on the 2009 NAIP imagery' when errors were extensive and com- plicated (fig. 4) because fixing the existing data (reshape, split, re-attribute, and add new features) required significantly more effort than deleting the features and adding new features (method illustrated in fig. 5).

- We attributed features as 'absent on the 2009 NAIP imagery' when the entire road segment or a large portion of the road is not visible in the imagery, and we then stored these data in a different data set.

- When a small portion of a road was not visible in the imagery, we interpolated the digitization while assuming the feature exists on the landscape (fig. 6) and stored the road in the final data set without attributing as 'absent on the 2009 NAIP imagery.'

4. We use the attribute field, NOTES, in the updated roads data set to define deviations from rules outlined in our classification scheme and data assurance. One example we discussed earlier was when we needed to use 2006 NAIP imagery because the spatial accuracy of the 2009 imagery was larger than the NAIP 6-m horizontal accuracy standard (http://www.fsa.usda.gov/FSA/apfoapp?are $a=$ home\&subject $=$ prog\&topic $=$ nai $)$.

\section{Topology Rules}

We processed all data to meet pre-determined topology rules (table 4). These rules are used during the merging of data blocks and the snapping of roads to the state boundary and during the planarizing of features (that is, automating the splitting of linear features when they intersect one another, such as when one road crosses a second road but there is no arc intersection [that is, node]). These topology rules are necessary for using the data in GIS applications by BLM, as well as others, and they are important to establish for quality assurance.

\section{Quality Control}

We used a spatially stratified sampling design (quality control) for assessing the accuracy of the updated road features. First, we randomly selected five fully represented 7.5-minute (min) quadrangles within each 1:100,000 quadrangle index that are fully contained within Wyoming (fig. 7). Second, a single point was randomly located along each individual line feature within the selected 7.5-min quadrangles, resulting in a total of 105,286 points. The complete data set of randomly generated points were subsampled (50 percent) to reduce the sample size and thereby allowing a more reasonable size for quality control, yet maintaining a size large enough for a statistically significant assessment. Third, the subsampled point data set $(54,257$ points) was used to evaluate attribute accuracy, spatial accuracy (considered accurate if within $10 \mathrm{~m}$ ), and commission 


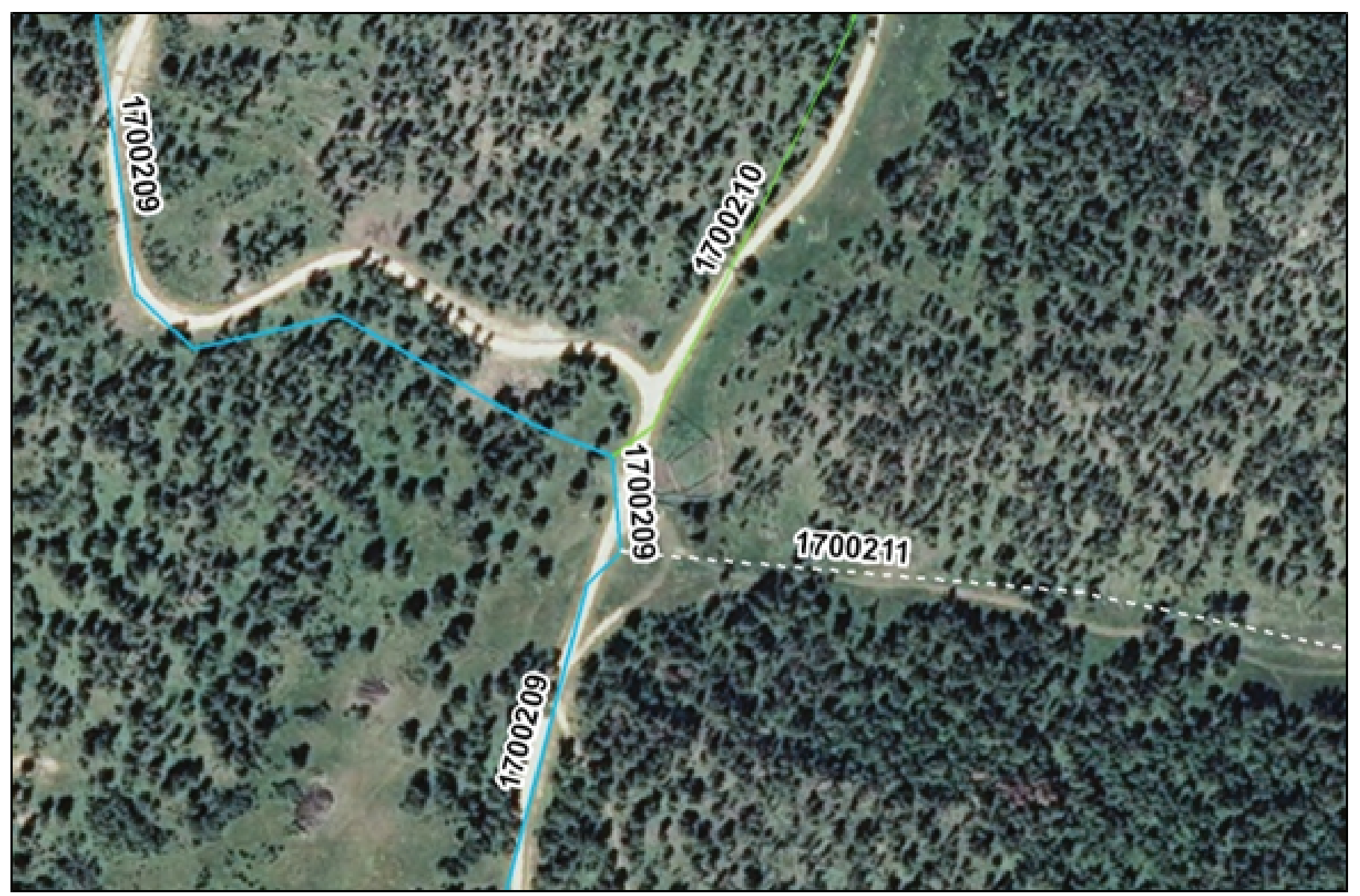

Figure 3. Difficulties distinguishing between classes '1700210' and '1700209'.

(attribute and spatial accuracy both failed) at their respective locations. Fourth, we identified omission errors for each randomly selected 7.5-min quadrangle while visually inspecting each fully selected 7.5-min quadrangle using the same scale established for developing the data $(1: 4,000)$.

\section{Results and Discussion}

The final updated 2009 NAIP roads data set delivered to the Wyoming BLM state office was compared aspatially with the pre-existing BLM roads data set. The largest changes observed occurred within road classes '1700210,' '1700211,' and '211TT,' as observed in table 5. These results do not describe whether the GIS data were re-shaped for each road class, but they demonstrate the distribution of linear distances between classes that we changed. The updated roads data also contains approximately 30,000 kilometers of 'new' roads relative to the pre-existing roads data.

We assessed our quality control results by summarizing the amount and proportion of errors as well as how these errors were spatially distributed. The identified errors provide details on how well we updated the data, and they identify errors that we then corrected within the final product release. Table 6 summarizes the number of features evaluated with the sampling design, as well as, the results from the accuracy assessment. In general, we found few spatial and aspatial errors in our digitization process. As a result, figures 8-10 show counts of errors instead of percent errors. Omission errors (fig. 8) generally correspond to areas where the most amount of digitization occurred (for example, northeast Wyoming). The aspatial (fig. 9) and spatial (fig. 10) errors are also very similar with each other but these do not necessarily match where the greatest spatial changes occurred (figs. 11-13). The maps of the eastern half of Wyoming shows where updates to the roads were the greatest and due to all the updates within this region, the increased errors are expected. Eastern Wyoming, and particularly northeastern Wyoming, has the least accurate road data, and these inaccuracies contributed to the amount of change compared to the 2009 NAIP imagery, and therefore, additional effort is necessary to update this region. However, our quality control indicates minimal errors with the omission, commission, spatial, and aspatial assessments for the updated 2009 NAIP roads data set developed for the BLM Wyoming State Office. 


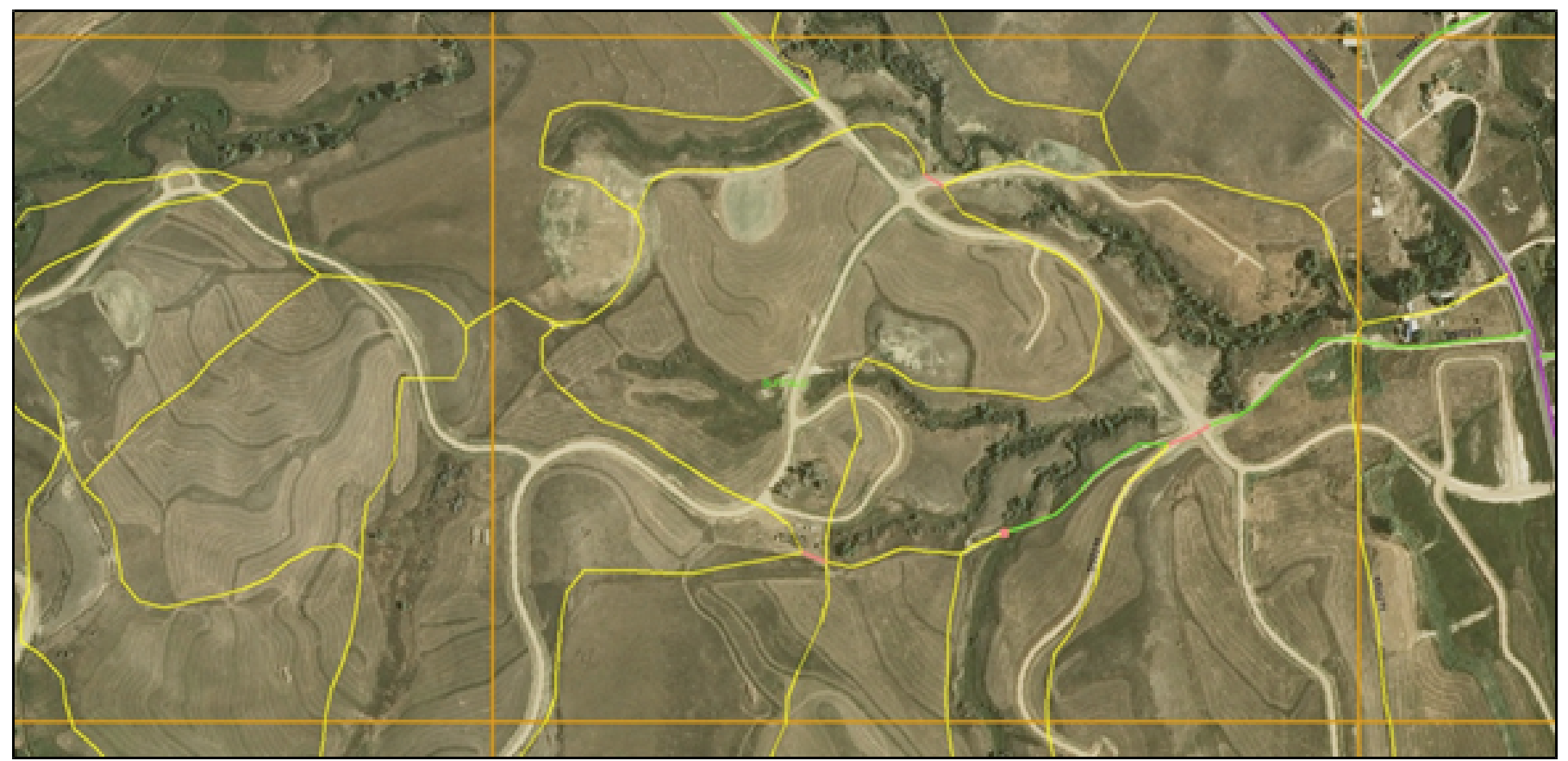

Figure 4. Example where we did not use the 'absent on the 2009 NAIP imagery' rule because fixing these roads will require more time than if they were deleted and re-digitized from scratch.

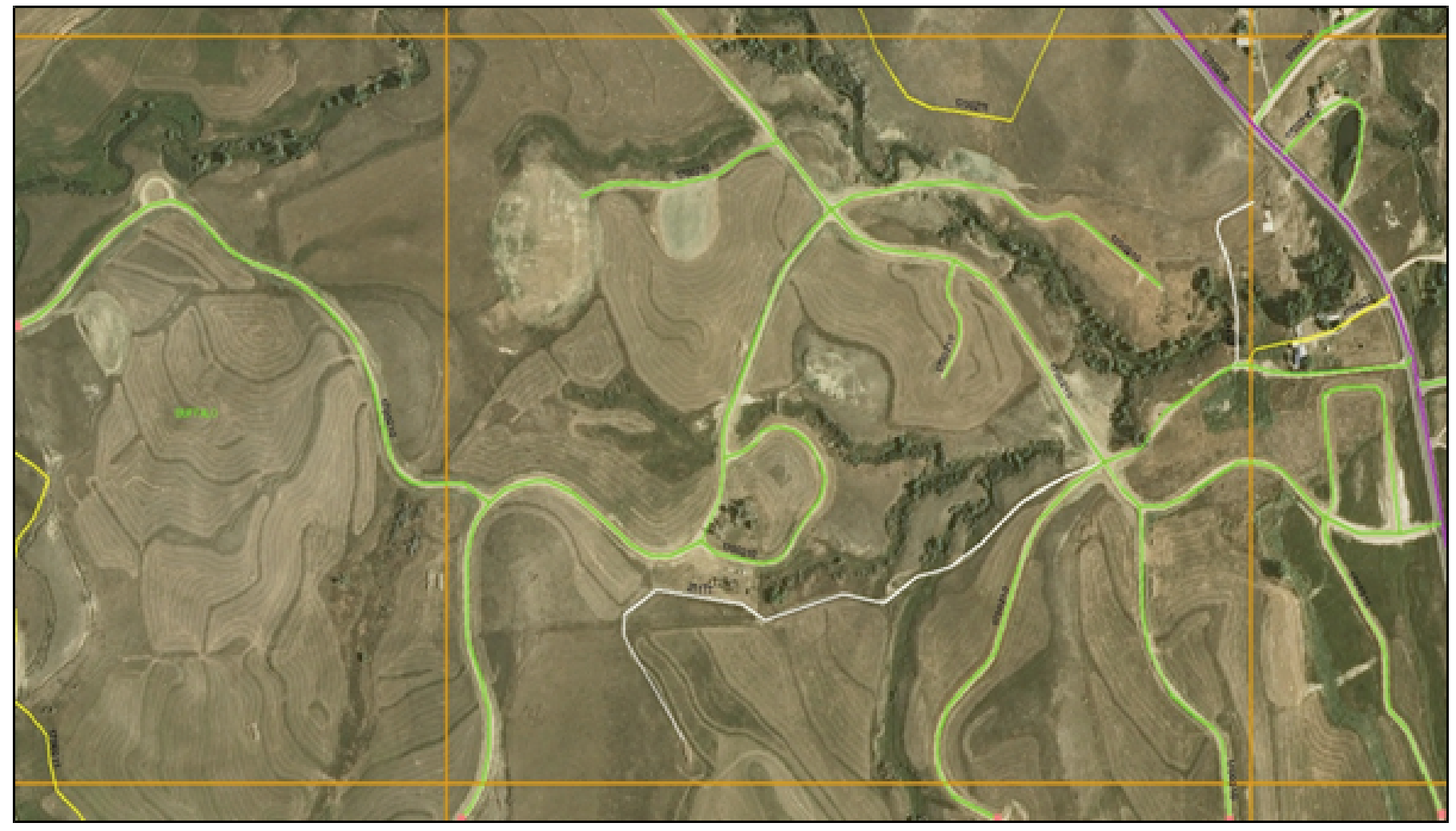

Figure 5. An outcome where we deleted pre-existing roads and re-digitized the roads versus attributing the pre-existing roads as 'absent on the 2009 NAIP imagery', and then fixing those roads to match the imagery. 

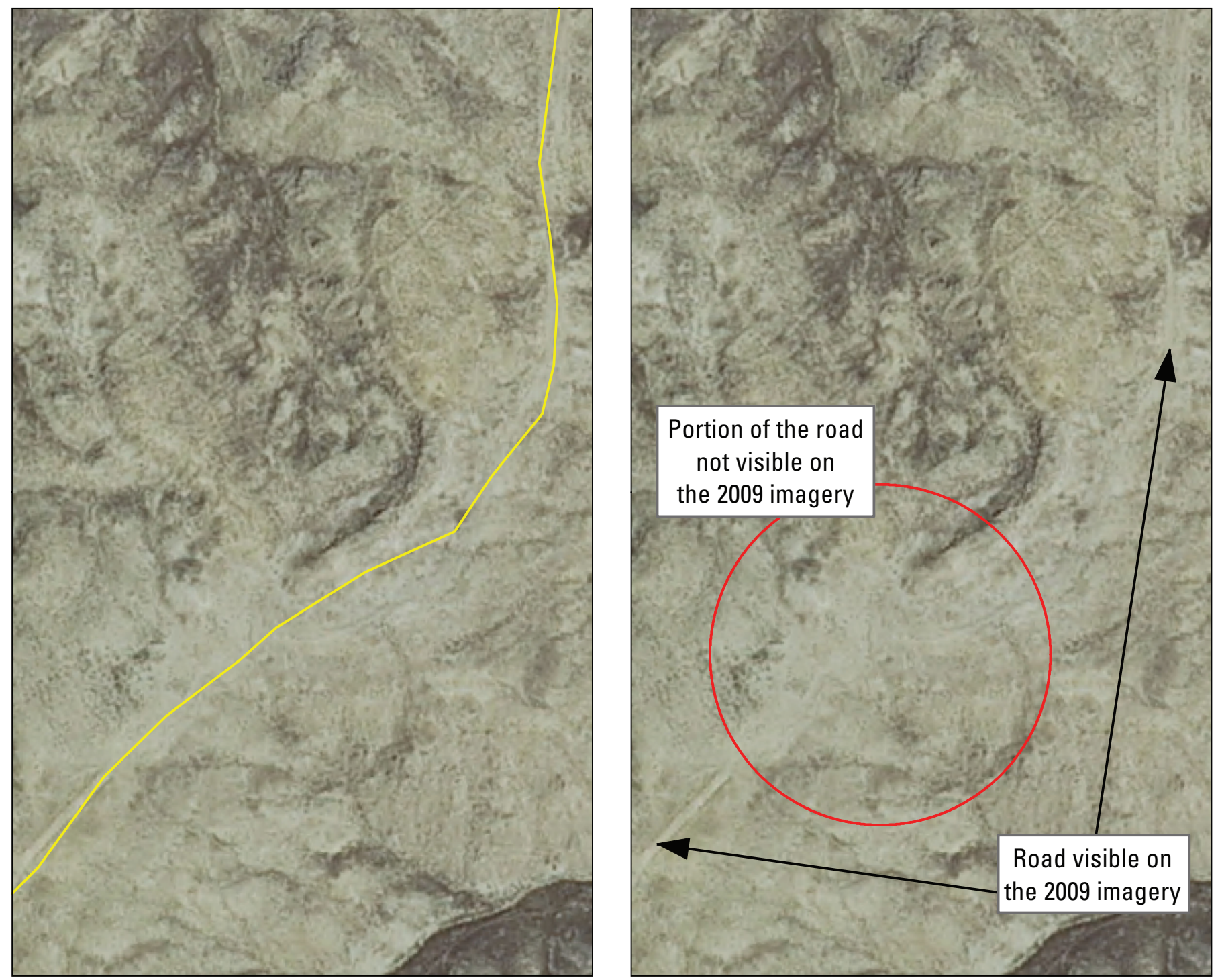

Figure 6. An outcome where we deleted pre-existing roads and re-digitized the roads versus attributing the pre-existing roads as 'absent on the 2009 NAIP imagery', and then fixing those roads to match the imagery. 
Table 4. Topology rules enforced on the updated 2009 National Agriculture Imagery Program roads data set.

\begin{tabular}{|c|c|}
\hline Topology rule & Definition \\
\hline Must be larger than cluster tolerance & $\begin{array}{l}\text { Require that a feature does not collapse during the validation process. This rule is manda- } \\
\text { tory for a topology, and applies to all line and polygon feature classes. }\end{array}$ \\
\hline Must not overlap & Require that lines do not overlap with lines in the same feature class. \\
\hline Must not intersect & Line features must not cross or overlap each other. Lines can share endpoints. \\
\hline Must not have pseudo-nodes & $\begin{array}{l}\text { A line must touch more than one line from the same layer at its endpoints. We only im- } \\
\text { posed this rule on roads with similar attributes. }\end{array}$ \\
\hline Must not have dangles & $\begin{array}{l}\text { Line feature must touch lines from the same feature class at both endpoints. We only im- } \\
\text { posed this rule on roads that were not legitimate dangles. Exception: leave cul-de-sacs } \\
\text { as dangling features. Dangles refer to arcs that do not butt against another arc. }\end{array}$ \\
\hline Must not self-overlap & Line features cannot be coincident, but they can cross or touch each other. \\
\hline Must not self-intersect & A line feature must not intersect itself. \\
\hline Must be single part & A line feature must not have more than one part. \\
\hline
\end{tabular}

To quantify the amount of change between the preexisting road data and the updated road data, we evaluated the spatial overlap between the two data using three different fuzzy-logic parameters. When we examined how closely the updated roads spatially match the pre-existing roads within $1 \mathrm{~m}$ of each other, we found that approximately 48 percent of all updated roads had a positional shift of more than $1 \mathrm{~m}$ (table 6 and fig. 11). Using a 5-m threshold, we found that twenty-six percent of the updated roads resulted in changes greater than 5 $\mathrm{m}$ (table 6 and fig. 12). Using a 9-m threshold, we found that approximately 17 percent of all updated roads had a positional shift of more than $9 \mathrm{~m}$ (table 6 and fig. 13). We selected the three thresholds $(1 \mathrm{~m}, 5 \mathrm{~m}$, and $9 \mathrm{~m})$ because these provide insight on the amount of change that occurred from updates.
A 1-m threshold first seemed reasonable, but we believe most of these changes are likely due to planarizing the data. The 5-m threshold likely represents a realistic measure of change because planarizing the data will not cause shifts of this magnitude. We chose $9 \mathrm{~m}$ because our threshold for updating features was set at approximately $10 \mathrm{~m}$ spatial difference between the GIS data and the 2009 NAIP imagery, and therefore, this assessment does not capture spatial differences less than 10 $\mathrm{m}$. These results indicate that the digitizing efforts changed approximately 26 percent of the roads (5-m threshold, fig. 12) relative to the original GIS product. Figure 13 illustrates which areas within the state required significant changes relative to the pre-existing road data. 


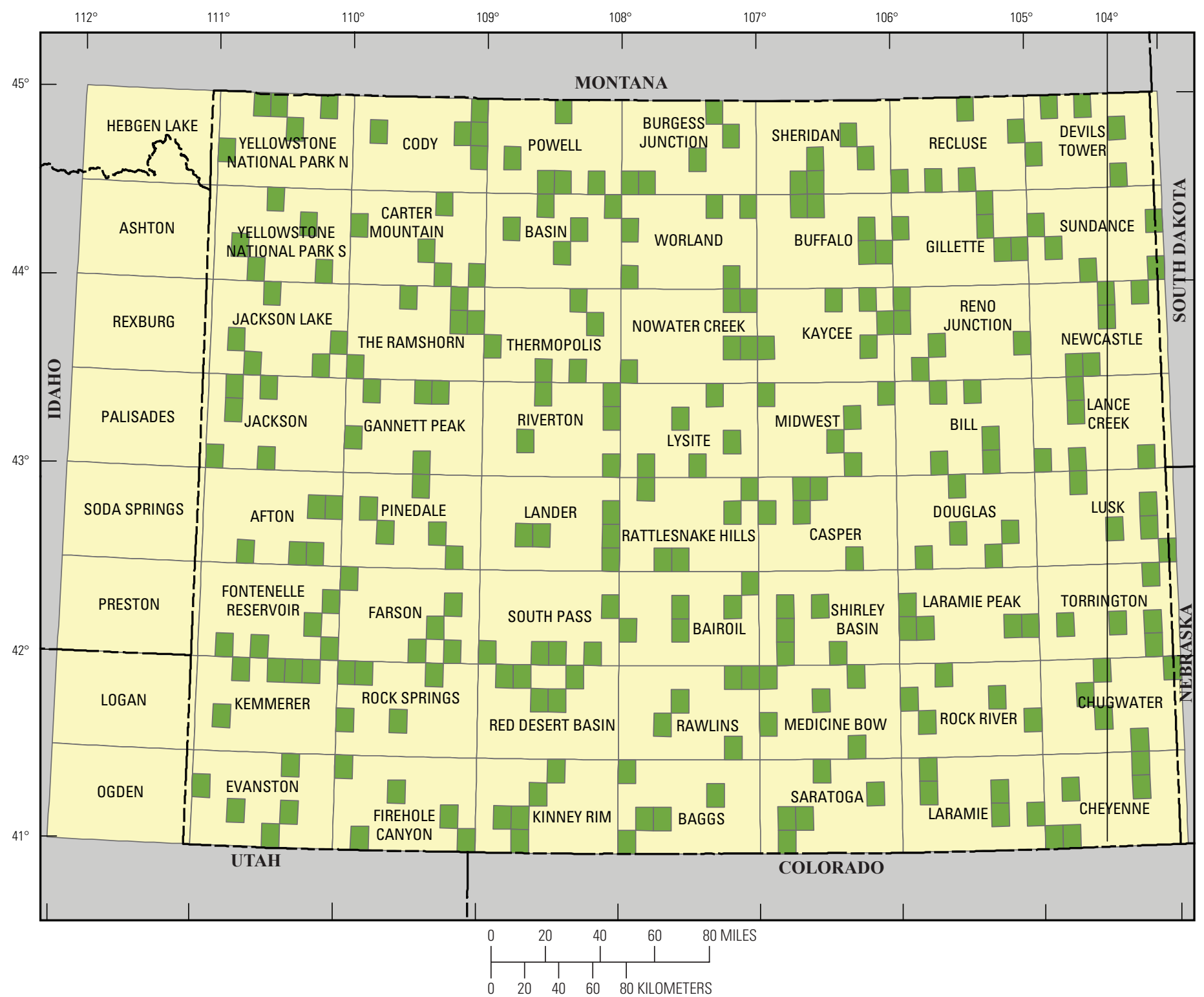

EXPLANATION

7.5-minute quadrangle

100,000 -scale quadrangle

boundary

KINNEY RIM 100,000-scale quadrangle

identifier

Figure 7. Distribution of five randomly selected 7.5-minute quadrangles within each 1:100,000-scale quadrangle used for evaluation and assessment of roads digitized within the state of Wyoming. 
Table 5. Linear distances quantified for pre-existing and updated 2009 National Agriculture Imagery Program roads across Wyoming. (BLM, Bureau of Land Management; km, kilometers)

\begin{tabular}{|c|c|c|c|}
\hline Entity_Label & BLM Road Class Definition & $\begin{array}{l}\text { Linear distance }(\mathrm{km}) \\
\text { for original data set }\end{array}$ & $\begin{array}{l}\text { Linear distance }(\mathrm{km}) \\
\text { for updated data set }\end{array}$ \\
\hline & No attribute assigned & 34.8 & 0 \\
\hline 1700201 & Primary highway, hard surface & $1,435.9$ & $1,427.3$ \\
\hline 1700203 & Primary highway, hard surface-lanes divided & 92.9 & 92.8 \\
\hline 1700205 & Secondary highway, hard surface & $9,244.5$ & $9,435.1$ \\
\hline 1700209 & Light duty, hard, or aggregate surface & $33,313.1$ & $33,296.6$ \\
\hline 1700210 & Streets, roads graded, drained, natural surface & $62,207.5$ & $101,611.9$ \\
\hline 1700211 & Four-wheel drive, rough bladed or two-tracked surface & $288,691.4$ & $269,069.3$ \\
\hline $211 \mathrm{TT}$ & Newly added (per 2009 NAIP) two-track features & 0 & $9,995.0$ \\
\hline \multirow[t]{2}{*}{1700402} & Primary highway, hard surface (road ramps only) & 341.9 & 346.8 \\
\hline & Distance of all road classes & $395,362.0$ & $425,274.7$ \\
\hline
\end{tabular}

Table 6. Summary statistics quantified for original and updated road data across the state of Wyoming. $(\%$, percent; km, kilometer)

\begin{tabular}{ll}
\hline \multicolumn{1}{c}{ Definition } & \multicolumn{1}{c}{ Summary } \\
\hline Number of 1:100,000 quadrangles falling within Wyoming & 64 \\
Number of 7.5-minute quadrangles falling within Wyoming & 1,824 \\
Percentage of 7.5-minute quadrangles evaluated & $15.5 \%$ \\
Total number of omission features (fig. 8) & 2,274 \\
Total length of commission features & $224.8 \mathrm{~km}$ \\
Overall proportion of incorrect attributes (fig. 9) & $(1,267 / 54,257)=2.3 \%$ \\
Overall proportion of incorrect spatial locations (fig. 10) & $(1,112 / 54,257)=2.0 \%$ \\
Distance of modified and new roads; fuzzy logic 1 m (fig. 11) & $203,770.2 \mathrm{~km}(48.1 \%)$ \\
Distance of modified and new roads; fuzzy logic 5 m (fig. 12) & $111,680.9 \mathrm{~km}(26.3 \%)$ \\
Distance of modified and new roads; fuzzy logic 9 m (fig. 13) & $73,283.5 \mathrm{~km}(17.2 \%)$ \\
\hline
\end{tabular}




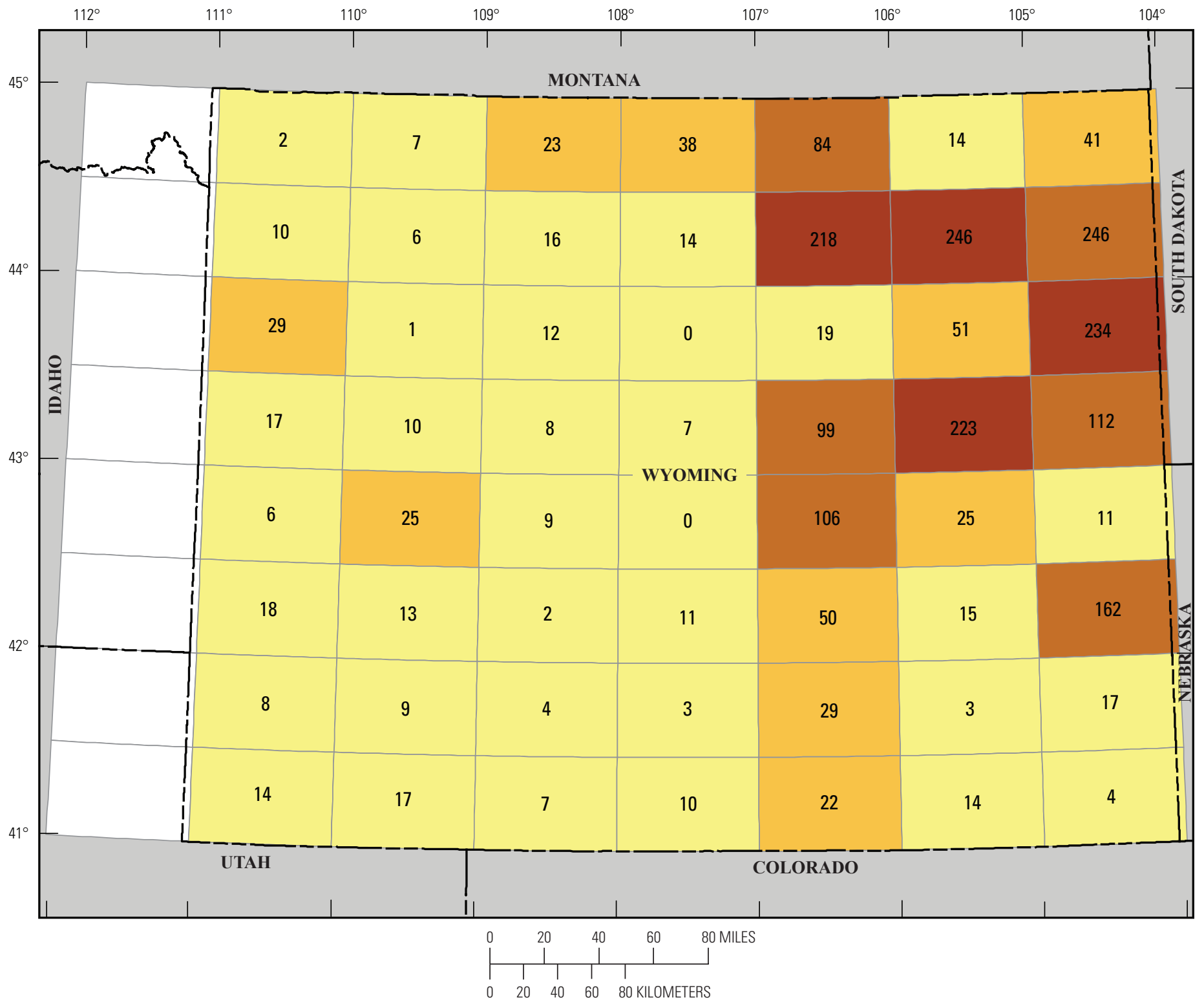

EXPLANATION

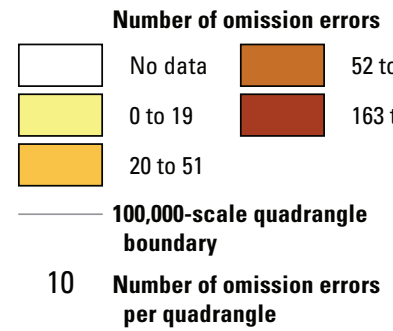

Figure 8. Distribution and the number of omission errors by 1:100,000-scale quadrangle for roads digitized within the state of Wyoming. 


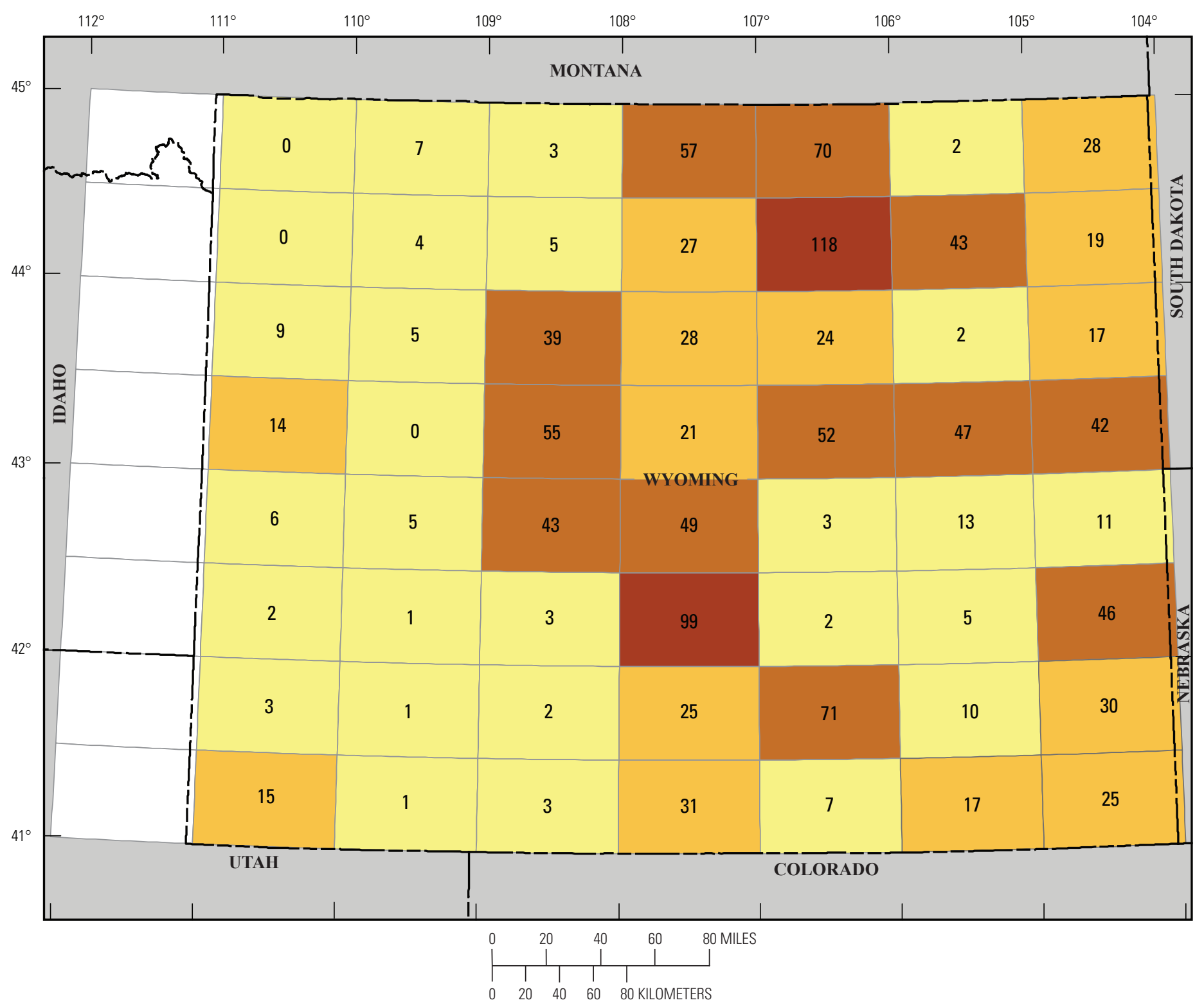

\section{EXPLANATION}

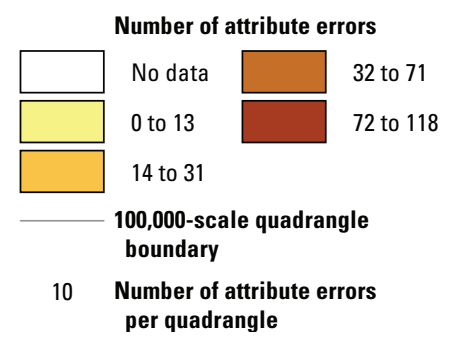

Figure 9. Distribution and the number of aspatial errors by 1:100,000-scale quadrangle for roads digitized within the state of Wyoming. 


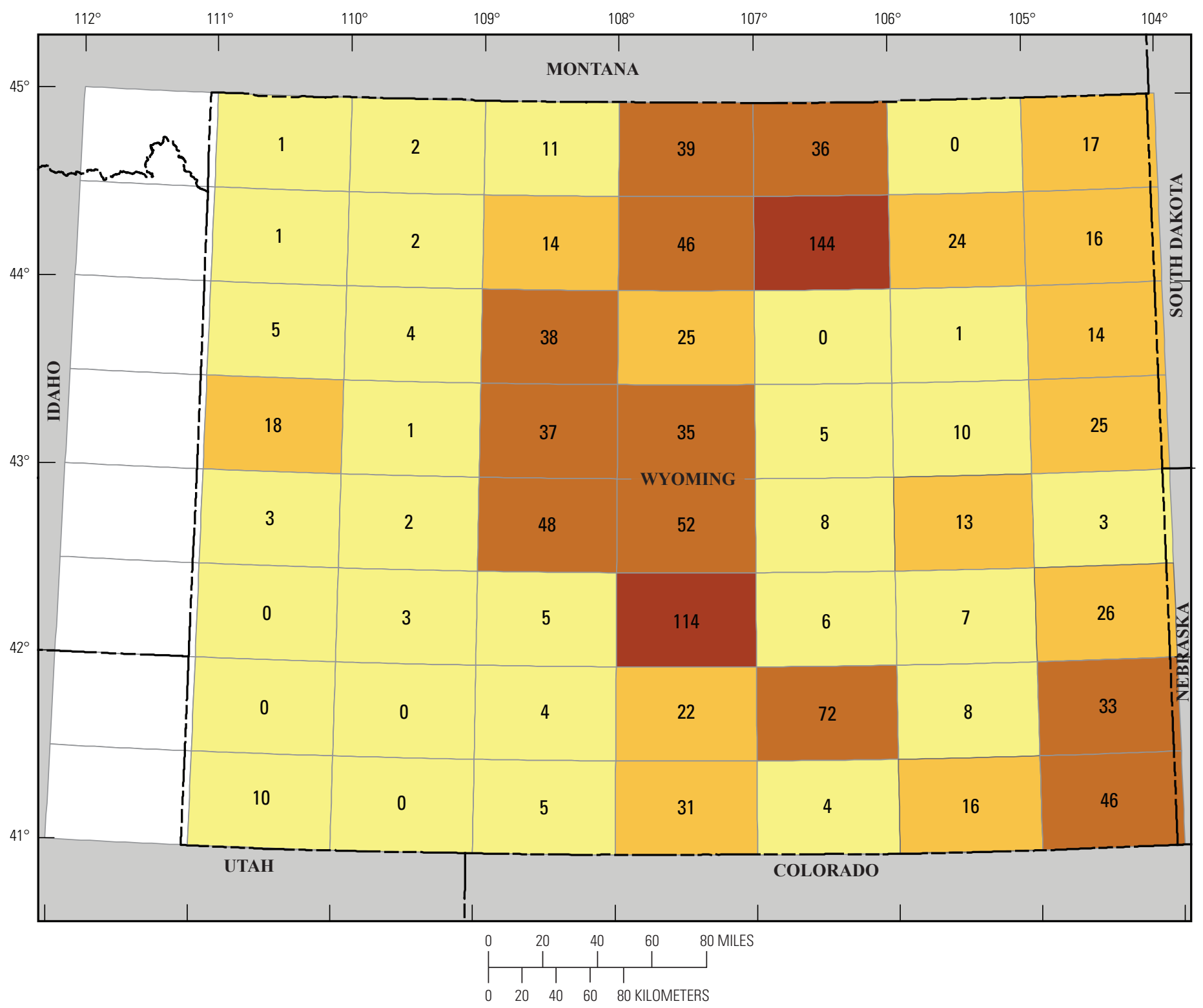

EXPLANATION

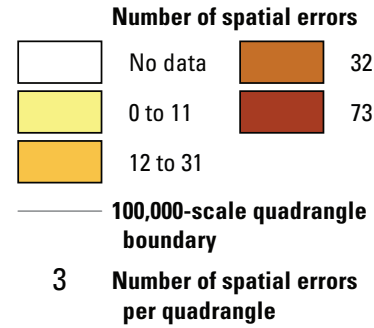

Figure 10. Distribution and the number of spatial errors by 1:100,000-scale quadrangle for roads digitized within the state of Wyoming. 


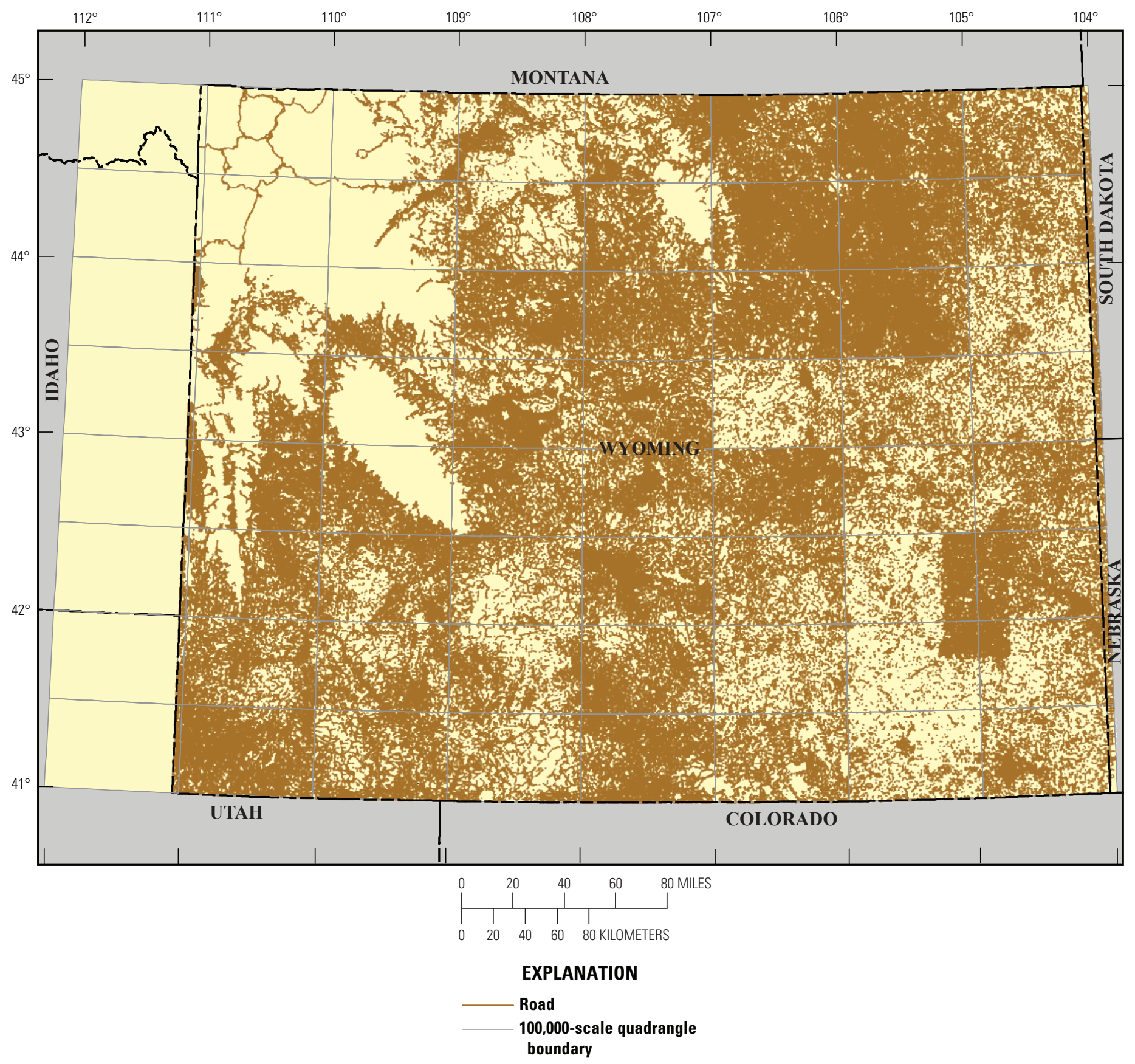

Figure 11. Distribution of roads modified or added relative to original data set while assuming a fuzzy logic of 1 meter. 


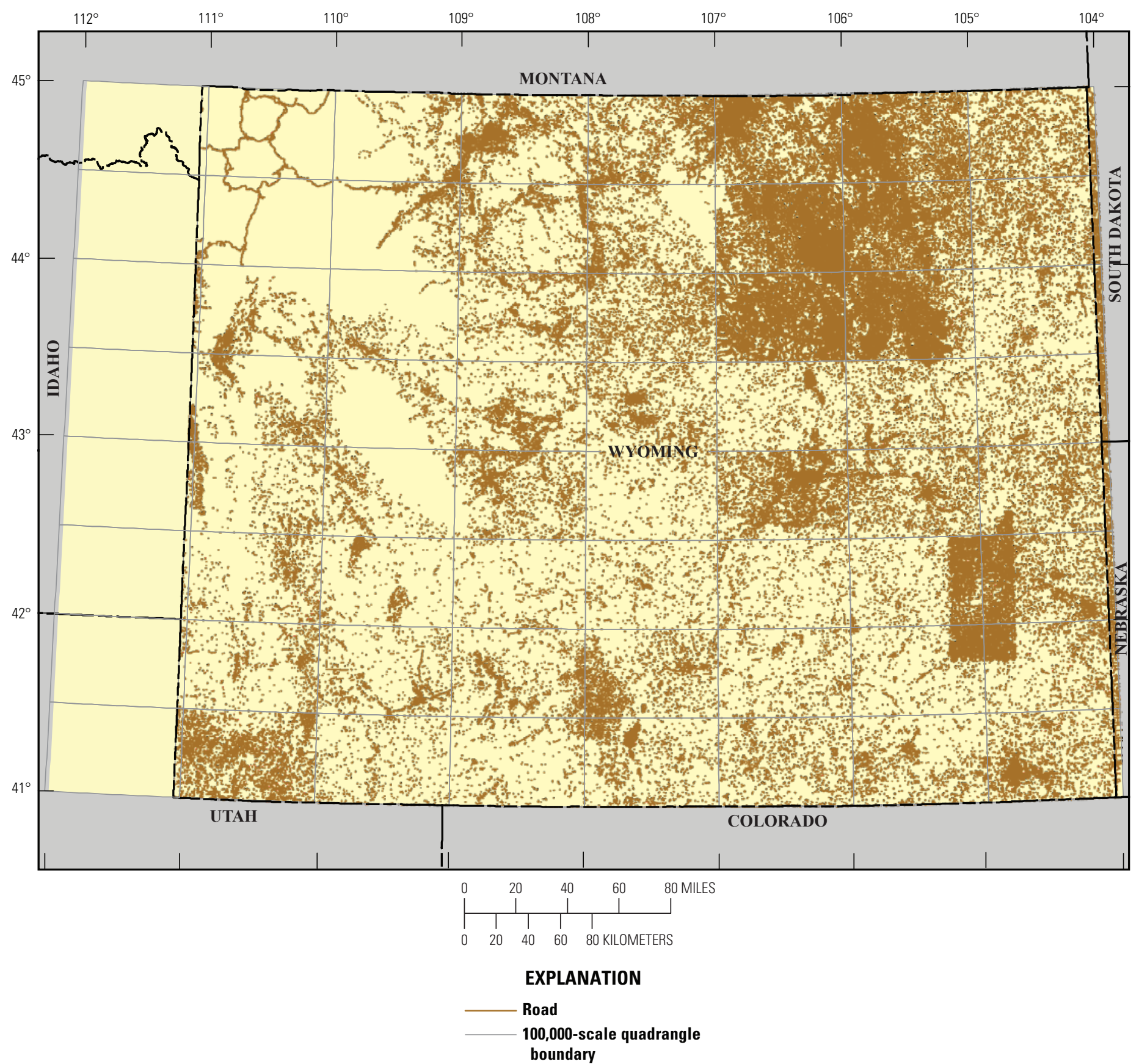

Figure 12. Distribution of roads modified or added relative to original data set while assuming a fuzzy logic of 5 meters. 


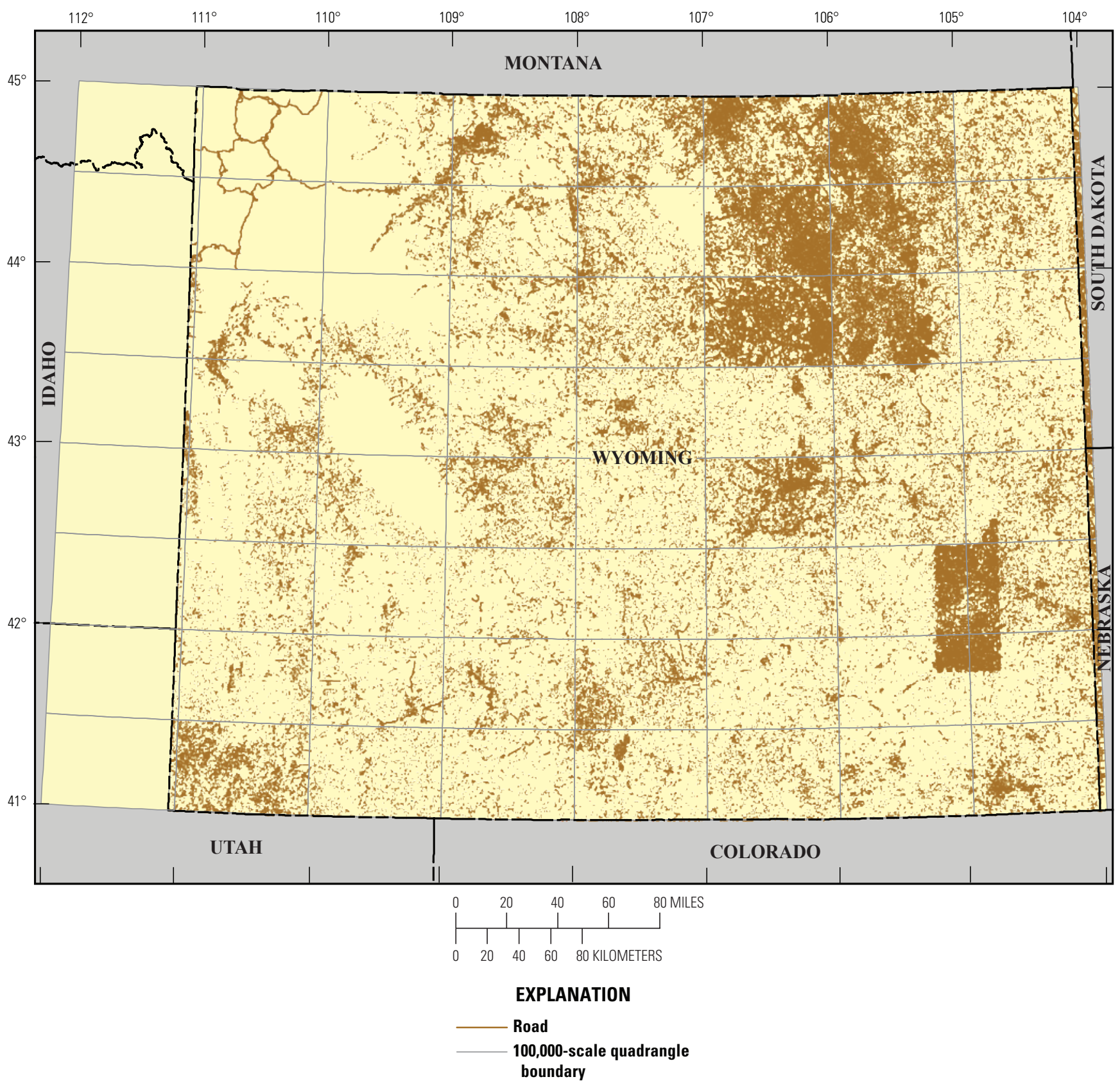

Figure 13. Distribution of roads modified or added relative to original data set while assuming a fuzzy logic of 9 meters. 


\section{Products}

Products associated with this report include a file geodatabase (DS821 WYRoads 2009.gdb) with a single feature class representing road centerlines, the corresponding Federal Geographic Data Committee (FGDC) metadata in XML format, and supporting data layers used during data base development. Because we include the topology of these data, it is necessary to use a file geodatabase. Data sets in the file geodatabase (version ArcGIS 10.0) include:

1. WY_Roads_2009: feature class representing road centerlines and its associated FGDC compliant metadata in XML format (and ArcGIS internal FGDC format).

2. WY_Roads_2009_Topology: feature class topology used to validate WY Roads 200 We provide this data set because it demonstrates that we addressed all topology exceptions (no topology errors are represented in the topology rule set) and so data users can maintain the same topology rules if updating the data.

3. In addition to providing all deliverables to the BLM, USGS is hosting all data products on the USGS ScienceBase web site (https://www.sciencebase.gov/).

\section{Future Efforts}

Follow-up work may entail updating the 2009 Wyoming road data using 2012 NAIP. If completed, BLM will have one of the most complete and current road data sets available in any U.S. state. The Bureau of Land Management, other land managers, and researchers can use these existing and future products to support important studies and management decisions regarding land use changes, transportation and planning needs, transportation safety, wildlife applications, and other studies.

\section{Disclaimers}

Any use of trade, firm, or product names is for descriptive purposes only and does not imply endorsement by the U.S. Government. Although these data have been processed successfully on a computer system at the USGS, no warranty expressed or implied is made regarding the display or utility of the data on any other system, or for general or scientific purposes, nor shall the act of distribution constitute any such warranty. The USGS shall not be held liable for improper or incorrect use of the data described and/or contained herein. Maps provided within this document are not for navigational use.

\section{References Cited}

U.S. Geological Survey, 1998, Attribute coding —-Standards for digital line graphs, part 3 of National Mapping Program Technical Instructions: U.S. Geological Survey, National Mapping Division, 173 p.
Publishing support provided by:

Denver Publishing Service Center

For more information concerning this publication, contact:

Center Director, USGS Fort Collins Science Center

2150 Centre Ave., Bldg. C

Fort Collins, CO 80526-8118

(970) 226-9398

Or visit the Fort Collins Science Center Web site at: http://www.fort.usgs.gov/ 
